\title{
On Developing Students' Spatial Visualisation Ability
}

\author{
Dwi Afrini Risma ${ }^{1}$, Ratu Ilma Indra Putri $^{2} \&$ Yusuf Hartono ${ }^{2}$ \\ ${ }^{1}$ Graduate student of International Master Program on Mathematics Education Sriwijaya University, Indonesia \\ in colaboration with Utrecht University, the Netherlands \\ ${ }^{2}$ Mathematics Education Department, Sriwijaya University, South Sumatera, Indonesia \\ Correspondence: Dwi Afrini Risma, Graduate student of International Master Program on Mathematics \\ Education Sriwijaya University, Indonesia in colaboration with Utrecht University, the Netherlands. E-mail: \\ dwiafrinirisma02@gmail.com
}

Received: June 12, 2013 Accepted: July 15, 2013 Online Published: August 16, 2013

doi:10.5539/ies.v6n9p1 URL: http://dx.doi.org/10.5539/ies.v6n9p1

\begin{abstract}
This research aims at studying on how students develop their spatial visualisation abilities. In this paper, one of five activities in an ongoing classroom activity is discussed. This paper documents students' learning activity in exploring the building blocks. The goal of teaching experiment is to support the development of students' spatial visualisation ability and to study about how students visualise and interpret the building blocks. The analysis of the activity is focused on exploring how the building blocks activity develop students' spatial visualisation, various way of students' interpretation and visualisation of building blocks, and how teacher affect the way students visualise and interpret the building blocks. The results of this study show that the building blocks activity supports the development of students' spatial visualisation ability.
\end{abstract}

Keywords: spatial visualisation, spatial ability, building block, design research

\section{Introduction}

Although we are live in a three-dimensional world, students are always presented with two-dimensional visualisation in their mathematics textbooks (Ben-Haim, Lappan, \& Houang, 1985). In early mathematics material, students often deal with 2-dimensional drawing such as in geometry materials, and in measurement topic. Many mathematical topics such as geometry require visualising abilities but many students cannot visualise three-dimensional objects in a two-dimensional perspective (Idris, 1998). Students are always forced to understand 2-dimensional representation of solid object which sometime are isometric drawing and sometime turn into horizontally. In order to understand these drawing students need to have good spatial visualisation ability.

A lot of research has proven how spatial visualisation plays important roles in developing students' mathematical thinking. Pittalis \& Christou (2010) research finding claimed that spatial abilities constitute a strong predictor of students' performance in the four types of reasoning in 3D geometry. Battista (1990) indicated spatial ability (including spatial visualisation) as one of the factors that affect success in geometry and geometric problem solving. Hegarty \& Waller (2005) claimed that in general spatial ability together with intelligence and visual perception is required to develop mathematical thinking. Yet the development of students' spatial visualisation ability in Indonesian curriculum is still lack of attention.

In this paper, we present one of five instructional activities that conducted in a second cycle of an explanatory teaching experiment in developing students' spatial ability. In this activity, students work on spatial visualisation task by exploring building blocks. The purpose of this paper is to explore how the building blocks activity supports the development of students' spatial visualisation. We are also interested to know how students visualise and interpret the building blocks, and teacher roles in developing the way students interpret and visualise the building blocks. Therefore, we formulate the general research question as: How the building blocks activity supports the development of students' spatial visualisation ability?

\subsection{Spatial Visualisation Ability}

Spatial visualisation is one of the important factors in spatial ability. Spatial visualisation is defined and evaluated in many ways (Risma, Van Eerde, Abels, \& Putri, 2013). Lohman (1988, 2000) define spatial 
visualisation as the ability to comprehend imaginary movement in a three-dimensional space or the ability to manipulate objects in the imagination. Titus \& Horsman (2009) define spatial visualisation as the ability that involves skill to mentally manipulate and rotate an image into another arrangement and to mentally imagine what is inside of a solid object. Bertoline et al. (1995) describe visualisation as "the mental understanding of visual information" (Idris, 2006). In this study we use the definition given by Lohman $(1998,2000)$

\subsection{Spatial Visualisation Ability and Mathematical Performance}

A lot of studies have proven how spatial visualisation affects students' performance in mathematics (Clement \& Sarama, 2009; Pitta-Pantazi \& Christou, 2010; Battista, 1990; Holzinger \& Swineford, 1946; Hegarty \& Waller, 2005). Studies have shown that cognitive variable of spatial visualisation seems important in learning mathematics (Ben-Chaim, et al. 1985; Carment, 1989; Idris, 1998 in Idris 2006). Pitta-Pantazi \& Christou (2010) investigated the relation of students' spatial and object visualisation with their creative and practical abilities in three-dimensional geometry. The result suggested that preferences and experiences in spatial visualisation significantly related to students' practical abilities in three-dimensional arrays of cubes. The Pittalis \& Christou (2010) findings claimed that spatial abilities constitute a strong predictor of students' performance in the four types of reasoning in 3D geometry. Battista (1990) indicated spatial visualisation ability as one of the factors that affect success in geometry and geometric problem solving.

Many researchers supported the statement that spatial ability is important to the development of mathematical thinking. Holzinger \& Swineford (1946) claimed that spatial visualisation ability is closely related to academic achievement, particularly to success in math and geometry. Hegarty \& Waller (2005) claimed that in general spatial ability together with intelligence and visual perception is required to develop mathematical thinking. Hegarty \& Waller (2005) supported that spatial visualisation abilities are important for both constructing and comprehending abstract spatial representations in mathematical problem solving. Revina et al. (2011) in her study claimed that spatial visualisation tasks help students to develop their conceptual understanding of volume measurement.

Regarding to these facts, the development of students' spatial visualisation can no longer be dismiss. Yet, the development of students' spatial visualisation ability in Indonesian curriculum is still lack of attention. Ben-Haim, et al. (1985), Gutierrez (1992), Ma, et al. (2009) pointed out that the representation of 3D object mean of a 2D figure demand considerable conventionalizing which is not trivial and not taught in school (Pittalis $\&$ Christou, 2010). For this reason, there is a need to explicitly interpret and utilize convention for drawing 3D objects explicitly; otherwise, students may misread a drawing and may not understand whether it represent a 2D or 3D object (Parzysz, 1988 in Pittalis \& Christou, 2010). Considering the importance of these aspects, a study based on Pendidikan Matematika Realistik Indonesia (PMRI) or Indonesian Realistic Mathematics Education principles is designed. PMRI is an approach in teaching mathematics that is adapted from of Realistic Mathematics Education (RME) approach (see Putri, 2011). In this study we develop a sequence of learning activities that combine two important spatial ability namely spatial visualisation and spatial orientation. These two components are integrated into some tasks to support the development of students' spatial ability. In this paper, the discussion is more focused on one of five instructional activities that conducted in a second cycle of an explanatory teaching experiment. The building block activity focus on developing students' spatial visualisation ability

\subsection{Building Blocks Activity in Developing Students' Spatial Visualisation}

Building block is an activity in which students are given a cubes or blocks and then they are asked to construct a building from the cubes or blocks. Many study shows how the building blocks activity support the development of students' spatial ability. Ben-Haim et al. (1985) suggests that, in order to be able to count the volume of an object made of small cubes, students need to be able to coordinate and integrate the views of an array either in real blocks arrangement or in drawing representation. Revina et al. (2011) found that building blocks activity could develop students' spatial visualisation and spatial structuring in volume measurement.

Furthermore, in children mathematics textbooks, we frequently find the visualisation of cube and building blocks. To be able to 'read' this visualisation, students need to have good spatial visualisation ability. For these reasons, in this study we design the building blocks activity to support the development of students' spatial visualisation ability.

\subsection{The Present Study}

The present study is a part of a design research project on developing students' spatial ability. This paper focuses on describing one of five instructional activities on the design research. This research involved 39 students of $3^{\text {rd }}$ 
grade of Elementary Students of 117 Palembang and a $3^{\text {rd }}$ grade classroom teacher. The aim of this present study is to explore how the building blocks activity supports the development of students' spatial visualisation. Therefore, we formulate the general research question as: How the building blocks activity supports the development of students' spatial visualisation ability?

We are also interested to know how students visualise and interpret the building blocks, and teacher roles in developing the way students interpret and visualise the building blocks. Therefore, we formulate the following sub- research questions:

\section{1) How students' visualise and interpret the building blocks}

2) How teacher's role in supporting the development of students' conceptual understanding in interpreting and visualising the building blocks

Apparently, design research is chosen as an approach to find the answers of these research questions.

\section{Method}

\subsection{Participant}

This study involves 39 of $3^{\text {rd }}$ grade students of State elementary school 117 Palembang that consisted ranging ages from 9 to 10 years. This study also involves a $3^{\text {rd }}$ grade classroom teacher of State elementary school 117 Palembang, Indonesia.

\subsection{Research Design}

This present study is a part of a design research project on developing students' spatial ability through spatial visualisation and spatial orientation task (see in Risma et al., 2012). PMRI is deliberately chosen as an approach in designing the instructional activities. The essential of design research is to provide an empirically grounded theory about how mathematical instruction works in create a more effective learning activity (Gravemeijer \& Cobb, 2006). In this essence, the five instruction activities that were developed are to be implemented in the classroom and the data collected are to see how the design affects the efficiency in learning. Therefore, the present study focus on one of five instructional activities that conducted in a second cycle of an explanatory teaching experiment, namely building blocks activity. In this activity, students are provided with wooden cubes and students worksheet. The wooden cubes provided are constructed in to some building which is appropriate with the instruction given on the students' worksheet.

The purpose of the activity is to enable the student to make connection between different views of the building blocks and to identify the side views and the top view of the building blocks. Therefore, in this activity the students are asked to draw the side views (front view, back view, left view, and right view) and the top view of the building blocks. The learning activity was aimed to be done in 70 minutes-long meeting. However, due to some technical problems, we have to split the activity becomes two meetings. During learning in this activity, the students are grouped into some small groups of 3 or 4 students. In the building block activity, the students have to solve three problems. The first two problems are solved in the first meeting and the last problem is solved in the second meeting.

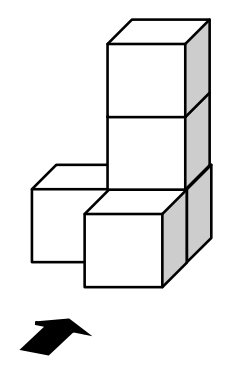

Figure 1. The first problem of student's task

The learning activity of the first meeting is started by introducing the context and the problem that should be solved by the students. In the first problem, the students are asked to construct a building blocks from a small wooden cubes as shown in the students' worksheet (see figure 1) and then draw its side views and top view. In the second problem, the students have to construct their own building blocks that consist of 5 wooden cubes and then draw its side views and top view. In The learning activity is stopped after 35 minutes. 
The second meeting is conducted ten days later. The learning activity is started by a classroom discussion and continued by solving the last problem. In the second meeting, the students are asked to construct their own building blocks from four wooden cubes and draw its side view and top view. This task should be done individually.

\subsection{Data Collection and Data Analysis}

Data are collected in two meetings of 35 minutes lesson and 35 minutes lesson. Before conducted the learning activity, researcher discuss the activity with teacher to help her in preparing the lesson. The role of researcher in the learning activity are to stand by, ask the students some additional questions, to observe the learning activity, to coordinate the activity, and to make last-minute change to the activity that is necessary for providing relevant information for research (Van Nes \& Van Eerde, 2010),

The learning activity is videotaped by two video recorders, one video recorder capture the whole classroom activity, and the other focus on target group. The video is segmented into clips based on sequences of observed interactions, negotiations and activities that appeared relevant to each didactical episode in the activity (Van Nes \& Van Eerde, 2010; Andrews, 2004; Powell, Francisco, \& Maher, 2003). During the learning activity, we also make some notes based on some important moments. All students' works are cross-interpreted to avoid subjectivity in interpretation. Together with the teacher, we discuss why a students' visualise in such way. To gain more insight on students' visualisation and interpretation, researcher conducted unstructured interview with some students. The interview is also aimed to clarify students' thinking and interpretation.

\section{Results and Discussion}

\subsection{How Students Visualise and Interpret the Building Blocks}

In this session, we focus the analysis on the students' works on the first meeting. As we addressed, in the first meeting students have to solve two problems. Since the second problem enables us to find several of building blocks construction, therefore in this session we focus the analysis and the discussion on the first problem. In the first problem, students are asked to construct the building blocks as shown in figure 1, and then draw its side views and top view. The students are provided with an example on how to draw the building blocks. In the students' worksheet, they are given the right view of the building blocks.

\subsubsection{The 'Normal' Side View of the Building Blocks}

We define the 'normal' side view of the cubes arrays as the side view of the building blocks that has no immersed (goes-in or goes out) part. In the first problem, there are two 'normal' side views namely right view and back view. We find that most of the students draw the side view of the building blocks correctly (see figure 2a). Yet, we also find a reversed drawing (see figure. 2b). It seems that these students disorient side view of the building blocks. We also find that some students draw the back view of the building blocks as three squares that are arranged vertically (see figure $2 \mathrm{c}$ ). The following figure show examples of students' drawing.

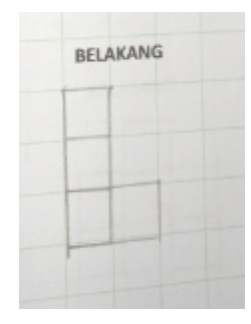

(a)

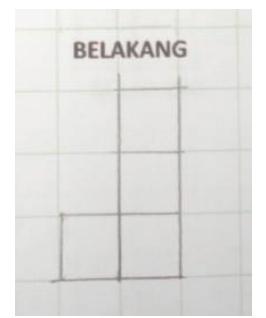

(b)

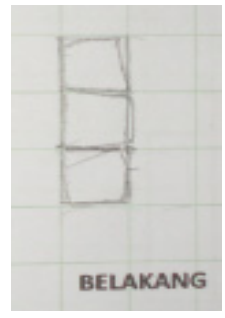

(c)

Figure 2. Examples of students' working on the first problem: (a) the correct drawing, (b) the reversed drawing,

(c) the three squares that are arranged vertically drawing

From the drawing, we can see how the students visualise the back view of the building blocks. Although most of students' drawings are correct, it leaves us some doubt on how the students interpret the building blocks. We consider that the example given presumably affect on the way students interpret and visualise the back view of the building blocks. The students who draw the reversed drawing may disorient the back view of the building blocks. Nevertheless, we also find that there are some students visualise the back view of the building block as the three squares that are arranged vertically (see figure 2c). To get more insight on this drawing we conduct an unstructured interview with one of the students who draw the building blocks as three squares that are arranged 
vertically. Yet, we cannot get clarification on why students draw the back view of the building blocks as three squares that are arranged vertically. It is because the student does not give clear answer why she draws in that way. She just keeps silence at that time. The following conversation is taken from researcher's field note.

1. Researcher: Why do you draw it in that way?

2. Salsabila : Because... (Silent) Hmm... (Pointing the building blocks) I don't know!

\subsubsection{The Goes-Out Part of the Building Blocks}

The term goes-out part rises when the students start working on drawing the front and left view of the building blocks. The students use this term to define the immersed part of the cubes. We find several variation of students' visualisation on the immersed part. The following pictures show the collection of students' visualisation on the goes-out part of the building blocks.

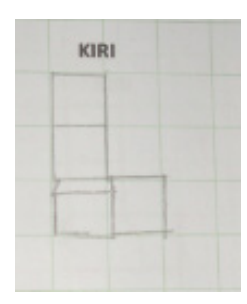

(a)

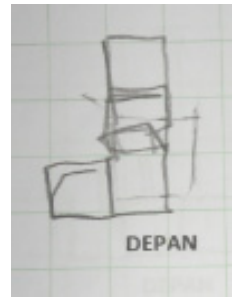

(b)

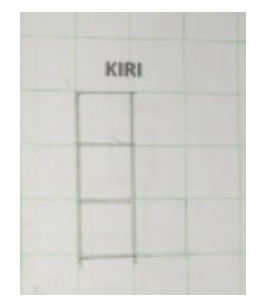

(c)

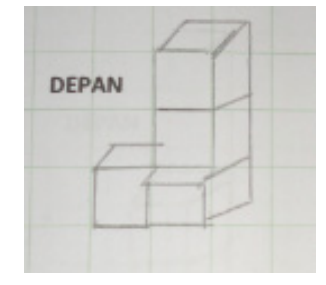

(d)

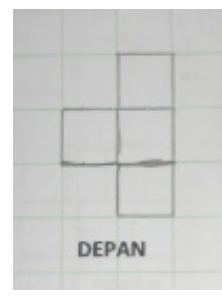

(e)

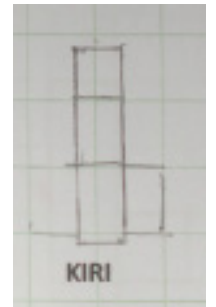

(f)

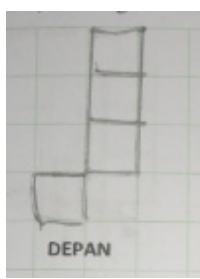

(g)

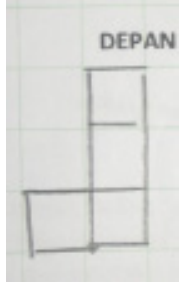

(h)

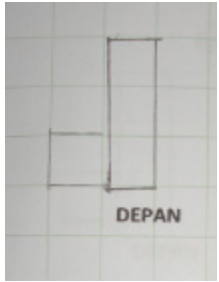

(i)

Figure 3. Examples of students' visualisation on the front view and the left view of the building blocks

From figure 3 we can see that the student interpret and visualise the front and the left view of the building blocks in a various way. Based on students' works, we categorise the way students interpreting the side view of a cube into four different ways of interpretation:

1. The side view is all parts of the building blocks that is visible if we see it from a certain side view, regardless there is immersed part or not. The students who use this definition only focus their visualisation on the part of the building blocks that is visible from the side view. These students ignore the fact that there is immersed part in the building blocks. Figure 3.h and 3.i are the examples of students' interpretation by this definition.

2. The side view is all parts of the building blocks that are visible if we see it from a certain side view. These students interpret the front view of the building blocks as all of the area that is visible from front view. The students who use this definition always use the concept of perspective in their drawing. In visualise the front view of the building blocks they focus not only on the shape of the cube that is visible from the front view but also the fact that there is a distance between the shapes created by the immersed part. Figure 3.e, 3.f and 3.g are the examples of students' interpretation by this definition.

3. The side view is all part that may be visible from the side view. The way these students represent the side view of the building blocks is affected by the fact that there is immersed part on the building blocks. These students tend to ignore the fact that if they carefully observe the building blocks from the side view, they do not see the top side of the immersed cubes. Therefore, these students tend to visualise the immersed part of the building blocks as a three-dimensional drawings. Moreover, these students think that there is a need to show that there is a different in visualising the immersed part. Figure 3.a and 3.b are the examples of students' interpretation by this definition. 
4. The side view is the three-dimensional representation of the building blocks if we see it from the side view. The students who use this definition tend to draw the building blocks as the three-dimensional drawing (see figure 3.d). These students probably do not understand the instruction given by the teacher, or misinterpreting the term side view. We cannot derive more information about these students since their work show inconsistency. Logically, if they interpret the side view as state on the definition, we expect that they visualise both front view and left view as a three-dimensional drawing. In contrast, we find that none of the students, who visualise the front view as three-dimensional drawing, comes up with the three-dimensional drawing when they draw the back view of the building blocks.

Moreover, we also find another inconsistency on the way students interpret the immersed part of the building blocks. These students come up with different visualisation for similar problem. As an example, in one of the group we find that they draw the left view of the building blocks as shown in figure 3.c. Apparently, this group visualise the front view similar with figure 3.a and 3.f.

\subsubsection{The Top View of the Building Blocks}

In general, we see that the students tend to draw the top view of the building blocks as one square and three combined squares (see figure 4). The differences appear because of different level of understanding and interpretation. For those students who draw a square as the top view, this probably because in their thinking the top view is the top part of the cubes that is located on the top layer. Figure 4.f and 4.g are some examples of students' work that underlies on this thinking.

Furthermore, the students who draw three squares have higher level of understanding and interpretation. They define the top view of the building blocks as the part of the building blocks that is visible if they see it from the top. Figure 4.a, 4.b, 4.c and 4.d are some examples of students' work based on this understanding. The collection of students' visualisation on top view of the building blocks can be seen in figure 4 .

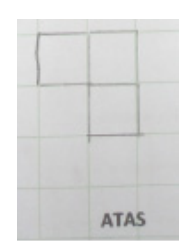

(a)

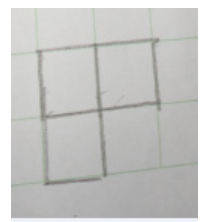

(b)

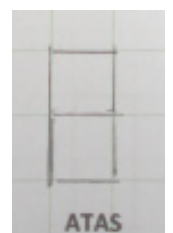

(e)

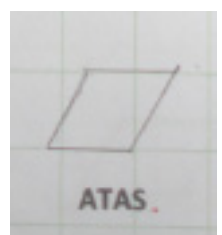

(f)

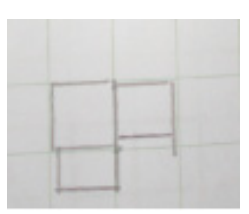

(c)

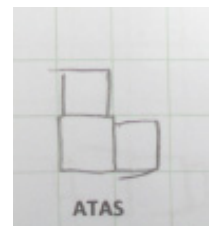

(d)

Figure 4. Examples of students' visualisation on the top view of the building blocks

From figure 4 we can see how vary students' visualisation. The correct visualisation is shown by figure 4.a. We find that although some students visualise the building blocks as three squares (see figure 4.a until 4.d), but each pictures shows different interpretation. As we address figure 4.a as a correct drawing, then figure 4.b, 4.c and 4.d show that the students disorient the direction shows by the example given in the students' worksheet. Figure 4.c and 4.d show perspective projection. The students who visualise the top view as shown in figure 4.c and 4.d consider the 'real' condition that there is a distance between the cube that is located on the top layer and the cubes that are located in the base layer.

In figure 4.f we can see that the students visualise the top view of the building blocks by a parallelogram. Based on the interview with the students after the learning activity, we find that they draw the parallelogram as the top view of the building blocks because that is how the example shows the top view of the top cube. Unfortunately, we cannot get clear description on how the students' thinking when they visualise the top view as shown in figure 4.e. 


\subsection{Classroom Discussion}

The learning activity is continued ten days later. We are afraid that this fact will bring some disadvantages in the learning process since ten days may create a gap in students' understanding. Considering the time gap and the result shown by students' work, we decide to change the learning trajectory. Instead of continuing students' working on the third problem, we have discussion session. The discussion is aimed to remind the students about the tasks that the students dealt in the previous meeting and to discuss about students' work.

In the beginning of discussion, the teacher asks one of the students to construct the first building blocks as they remember. One of the students, Rafi, raises his hand and constructs the building blocks on the playground. We find that Rafi and his friends remember well the tasks. The teacher then asks the students to draw the right view of the wall as what the students drew in their worksheets last meeting. Kharisya raises her hand and draw the right view of the building blocks. All of the students agree with Kharisya's drawing. It is because of Kharisya draws it correctly. Rafi raises his hand and draws the right view as shown in figure 4 (a). Next, the teacher asks whether any students have different opinion. Kharisya raises her hand and then draws the right view of the building blocks as shown in figure 4 (b). Teacher asks whether any students have different opinion once more. However, there is no other students raise their hands.

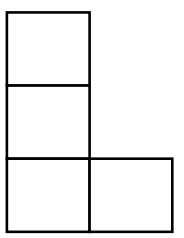

(a)

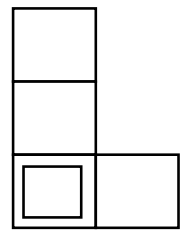

(b)

Figure 4. Students' drawing in the discussion: (a) Rafi's drawing, (b) Kharisya's drawing

The discussion is started by asking the students who agree with Kharisya's drawing and who do not. We find that all the girls agree with Kharisya's. Meanwhile all of the boys choose Rafi's drawing. The following discussion show how the students' discuss about the right view of the first building blocks.

1. Teacher : Now who can draw the front view?

2. Rafi : (raises his hand)

3. Teacher : Yes, Rafi! (pointing Rafi)

4. Rafi : (drawing the front view)

The classroom is too noisy. Rafi seems affected by his friends, so the teacher tries to get back the other students' attention and make them silent. While drawing the front view, Rafi frequently sees the building blocks to make sure that he draws it correctly. While trying to finish his drawing, Kharisya interrupts Rafi.

5. Kharisya: You should draw the goes out part! Your drawing is not looked like the cube house! (pointing Rafi's drawing by her right hand and the building blocks by her left side at the same time)

6. Rafi : (see the building blocks and continuing his drawing)

7. Teacher : Have you finish, Rafi?! Who do agree with Rafi's drawing?

8. Boys : I do!

9. Teacher : Who don't agree with Rafi's answer?

10. Rizki : I don't agree!

11. Teacher : Why don't you agree?

12. Rizki : Because the drawing is ugly!

13. Students : Huuuu...!!!

14. Teacher : Salsabila, do you think that Rafi's drawing is correct?

15. Salsabila : (silent)

16. Liza : It is ...... (inaudible)!

17. Teacher : Why it is incorrect, Liza? 
18. Liza : It is correct, I agree with Rafi's drawing!

Suddenly the students become so noisy, so the teacher has to make the students be quite. The teacher continues the discussion by asking who has different opinion.

19. Teacher : Why it is incorrect?

20. Najwa : (raises her hand) Because it is similar with Kharisya's drawing.

21. Teacher : So, how should be the drawing? You are free to give your opinion!

22. Kharisya : It is incorrect because there is the goes-out part in the cube house!

23. Teacher : So, how should be the drawing? Who want to draw it? If there is a mistake you may revise it. Iqbal, do you want to try it?

24. Iqbal : (shake his head)

25. Kharisya : (raises her hand)

26. Teacher : Come on Kharisya!

Kharisya draws the front view of the building blocks and explain her reason

27. Kharisya : Because there is goes-out part, we should draw it. But this one (pointing Rafi's drawing) does not show it.

Fragment 1. Students' Classroom Discussion

Soon after Kharisya gives her reason, the students are involved in the discussion. The students start arguing Rafi's drawing. Kharisya's statement successfully evokes the students' argumentation. Some students discuss this issue with the students who sit next to them; even Rafi seems doubt on his drawing but he does not change his answer. The teacher then show the picture of the building blocks which is taken from front view, and explain whose answer is correct, and why it is incorrect. Some students cannot accept the teacher's explanation and keep arguing it. However, the teacher stops the discussion and tells the students to do not protest anymore.

From the classroom discussion, we can see how the students develop their understanding on the concept of front view. Both Rafi and Kharisya show different level of understanding and interpretation. Rafi interprets the front view as the part that is visible if we see it from the front and ignores the fact that there is a goes-out part. Meanwhile, in Kharisya's opinion, we should draw the goes-out part in order to show how it is different with the others view. It gives us clearer description why some students draw the immersed part of the building blocks. We observe that during working on the first and second problems, most of the students do not close one of their eyes in observing the building blocks. The way Kharisya reason her answer show that what she 'see' the front view from the fact, not based on what she observe.

\subsection{How Students Interpret the Building Blocks after the Classroom Discussion}

After the students finish the classroom discussion, each students is given four wooden cubes. They are asked to construct a building block and then draw its side views and top view. This task should be done individually. Based on students' works we find that none of the students visualise the building blocks as three-dimensional representation drawing. It shows that the students start to develop their understanding on side view. We also see that there is a conceptual changing on defining the top view. We see that after the classroom discussion, the students define top view as the part of the building blocks that is visible if they see it from the top.

\subsection{Role of Teacher in Developing Students' Interpretation and Visualisation the Building Blocks}

We observe the focus group while working on the goes-out part. Before teacher interfere them, these students have finished drawing the front view of the building blocks. Figure 3 shows how focus group visualise the front view of the building blocks.

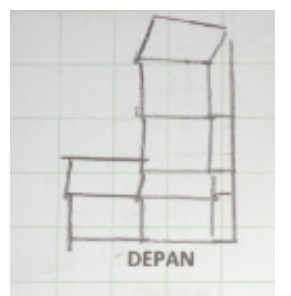

Figure 5. Students' visualisation on the front view of the building blocks 
From figure 5, we can see that the students visualise the front view of the building blocks in a 3-dimensional drawing. The following conversation is segmented while the students are working with the left view of the building blocks.

1. Teacher : Is it correct that the right view should be looked like on the worksheet?

2. Ajeng : Yes it is.

3. Teacher : So, how should be the left view looked like?

4. Ajeng : (observing the cubes arrays from the left you) How can I draw this part! (show the goes-out part). Should I draw the goes-out part?

5. Teacher : Why don't you kneel and see the cubes array from here?

6. Ajeng : (Ajeng kneels and see left view of the building blocks)

7. Teacher : Don't forget to close one of your eyes!

8. Ajeng : (Ajeng then close one of her eyes and continue the observing)

9. Teacher : Which part can you see?

10. Ajeng : This and this! (pointing the two upper cube and the part of the building blocks that is pointed in figure 6)

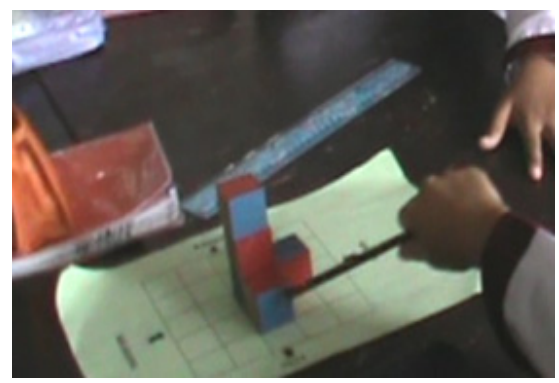

Figure 6. Ajeng is pointing the building blocks

11. Teacher : What about the next cube, can you see it?

12. Ajeng : This part?! (pointing the part of the building blocks that is pointed in figure 7) Yes, I can see it. But it is difficult to draw this part (pointing the top part of the goes-out cube). So, how should I draw it, $y a$ ?!

13. Teacher : I don’t know, just draw!

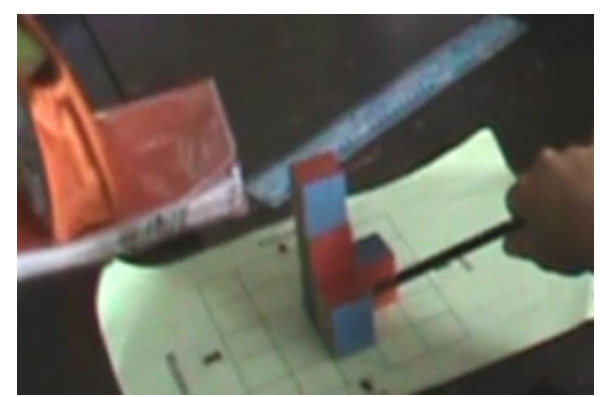

Figure 7. Ajeng is pointing the building blocks

Fragment 2. Teacher Interfere Students' Thinking

From this conversation we can see how the support the students in developing students' idea on defining the left view of the building blocks. Instead of giving a clear definition to the students that the side view of the cube is every part that is visible if they see it from the left view, the teacher ask the students' about which part that is visible if they see it from the left view. From dialogue no 5 and no 7 we can see how the teacher guide the students in observing the building blocks. Kneeling and close one of the eyes are the important things that should be done while observing the building blocks. Teacher makes sure that students do not miss these important 
points. We also have seen how the teacher plays dummies. When the students ask the teacher about how should be a proper drawing, she avoids giving the drawing and let the students think what should be the drawing. We conclude that there is an effort of teacher to develop the students' thinking by guiding the students in observing the building blocks. Furthermore, the teacher also wants the students to think and visualise the left view of the building blocks by themselves. In conclusion, the role of teacher in this case is to facilitate the development of students' thinking and to give space on students' creation.

After the students having this conversation, the students draw the left view of the cube as shown in the figure 8 . We see that there is big changing on the way students visualise the immersed part of the building blocks after the teacher interfere students' thinking. Previously, the students visualise the building blocks as three-dimensional representation (see figure 5). After the teacher interfere students' in working, the students' visualise the left view of building blocks as a two-dimensional drawings.

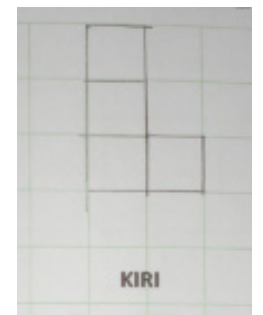

Figure 8. Students' visualisation on the left view of the building blocks

Teacher also plays important roles on classroom discussion activity. From the conversation on the "classroom discussion' section (Fragment 1), we can see how the teacher guiding the discussion and make sure that the learning activity can be proceeded by making the students focus again to the discussion. The teacher also encourages the passive students to be actively participating in the classroom discussion. The statement 'You are free to give your opinion!' in line 21 shows that the teacher give space for all of the students to discuss their opinion and thinking.

We frequently find that when the teacher cannot handle students' questions, she stops the discussion and tell the students to accept the answer. Next, she states that it is the correct answer. We realise that in this case the way teacher reacts on students' questions make the students stop thinking. As the result, we find that when students' work on the individual task, some students do not make their own building blocks construction. They construct the first building blocks and draw the side views and top view of the building blocks as same as what their friends drew in the black board. From this fact, we conclude that students' spatial visualisation cannot be develop through only the instruction. This fact support Gillespie (1995) who state that students' spatial visualisation ability cannot be improved by instruction (Suppiah, 2005).

\section{Conclusion}

Before elaborating the conclusion of this study, it should be noticed that the generalisation of the result in this present study is limited on a specific criteria and setting. We realise that the classroom setting that we have in conducting this study such as too many students in the classroom make the classroom environment become so noisy. This unsupported learning environment make the learning activity become less effective. The 10 days gap between two meetings presumably affect on how students react on the tasks. Therefore, the results of students' works in this present study probably different in different setting and scope. In the following section, we answer the research questions that we addressed.

\subsection{How Students Develop their Spatial Visualisation Ability by Experiencing the Building Blocks Activity?}

After experiencing this lesson, we have seen that the students actively use the spatial terms in discussing their work. In this lesson, the students also start to develop their understanding in identifying and observing the three dimensional object. Furthermore, we can find that the way students visualise the building blocks are increased. The fact, that there is no students represent the building blocks as a three-dimensional drawing after experiencing the building block activity, indicates that the students develop their spatial visualisation ability. Therefore, we conclude that spatial visualisation activities such as visualise the building blocks support the development of students' spatial ability. This conclusion in line with the result of Pittalis \& Christou (2010) which suggested that preferences and experiences in spatial visualisation significantly related to students' practical abilities in 
three-dimensional arrays of cubes. It also support Revina et al. (2011) and Ben-Haim (1985) which state that working on building blocks can support the development of students' spatial visualisation.

\subsection{How Students Interpret and Visualise the Building Blocks?}

Based on the analysis of students' working, we categorise the way students interpret and visualise the side view of building blocks into three general ways as follow.

1) Students visualise the side view of the building blocks as the squares, regardless it has an goes-out part or goes-into part.

2) Students visualise the goes-into and goes-out part in a three-dimensional drawing.

3) Students visualise the building blocks as three-dimensional drawing.

Moreover, we categorise students' interpretation and visualisation on top view into two general categories namely:

1) Students interpret the top view is the top part of the cubes that is located on the top layer.

2) Students interpret the top view as how the cubes arrays are visible if we see it from the top.

\subsection{How the Role of Teacher in Developing Students' Interpretation and Visualisation the Building Blocks?}

The result of this present study brings two important issues on the role of teacher in supporting the development of students' conceptual understanding in interpreting and visualising the building blocks. The first issue is on the way teacher guides Ajeng in developing her way in defining the side view of the building blocks. We have seen how the teacher supports Ajeng by giving some important questions and giving important instruction in observing. Furthermore, the teacher also gives space for the students to think and visualise the left view of the building blocks by playing dummies. In conclusion, the role of teacher in this case is to facilitate the development of students' thinking and to give space on students' creation.

Furthermore, there is an important role of teacher in the classroom discussion that should not be ignored. We have seen how teacher support every students to discuss about their answer and reason. It enables the students to discuss different strategies, different visualisation, and different interpretation. This approach enables students to have a constructive learning process because they are able to reflect on the differences.

The second issue should be brought is the way teacher anticipate students' questions. We have seen that teacher stops the discussion when she cannot anticipate students' questions. This probably happens because the teacher does not master the materials well. As the result, we find that some students think that it is the only correct answer and make the students become lazy. Moreover, the way teacher reacts on students' questions make the students stop thinking. From this fact, we conclude that students' spatial visualisation cannot be develop through only the instruction. This conclusion supports the result of Gillespie (1995) study that concludes that none of studies has found that spatial visualisation can be improved through instruction.

\section{Acknowledgement}

The authors would like to express our gratitudes to Ms. Fatmawati and her students for participating in this study. The instructional design central to this paper were elaborated in the curse of discussions with Mieke Abels, a teacher in Utrecht University, The Netherlands. The activitiess were conducted within the IMPoME program and were funded jointly by DIKTI, Indonesia and NUFFIC NESO, The Netherlands.

\section{References}

Andrew, P. (2004). International comparisons of mathematics teaching: Searching for consensus in describing opportunities for learning. In Paper presented to discussion group 11: International Comparisons in Mathematics Education, the Tenth International Congress on Mathematics Education (ICME-10). Copenhagen: Danish Technical University.

Battista, M. (1999). Fifth graders' enumeration of cubes in 3D arrays: Conceptual progress in inquiy based classroom. Journal for Research in Mathematics Education, 30(4), 417-448. http://dx.doi.org/10.2307/749708

Ben-Haim, D., Lappan, G., \& Houang, R. T. (1985). Visualizing Rectangular Solids Made of Small Cubes: Analyzing and Effecting Students' Performance. Educational Studies in Mathematics, 16(4), 389-409. http://dx.doi.org/10.2307/3482447 
Clement, D. H., \& Sarama, J. (2009). Spatial Thinking. In D. H. Clement, \& J. Sarama, Learning and Teaching Early Math: The Learning Trajectories Approach (pp. 107-122). New York \& London: Routledge Taylor \& Francis Group.

Gravemeijer, K., \& Cobb, P. (2006). Design research from the learning design perspective. In J. van den Akker, K. Gravemeijer, S. McKenney, \& N. Nieveen (Eds.), Educational Design Research (pp. 17-51). London: Routledge.

Hegarty, M., \& Waller, D. A. (2005). Individual differences in spatial abilities (P. Shah, \& A. Miyake, Eds.) Cambridge: Cambridge University Press.

Holzinger, K. J., \& Swineford, F. (1946). The relation of two bi-factors to achivement in geometry and other subjects. Journal of Education Psychology, 37, 257-265. http://dx.doi.org/10.1037/h0053536

Idris, N. (1998). Spatial visualization, field dependence/independence, van Hiele level, and achievement in geometry: The influence of selected activities for middle school students. Doctoral dissertation. http://dx.doi.org/9900847

Idris, N. (2006). Spatial Visualisation. In N. Idris (Ed.), Teaching and Learning of Mathematics: Making Sense and Developing Cognitive Abilities (pp. 56-70). Kuala Lumpur: Utusan Publisher \& Distributor Sdn Bhd.

Lohman, D. (1988). Spatial abilities as traits, process, and knowledge. In R. J. Sternberg (Ed.), Advances in the psychology of human intellegence (Vol. 40, pp. 181-248). Hillsdale: LEA. http://dx.doi.org/10.1017/CBO9780511807947.015

Lohman, D. (2000). Complex imformation processing. In R. J. Sternberg (Ed.), Handbook of Human Intellegence (pp. 181-248). Cambridge: Cambridge University Press. http://dx.doi.org/10.1007/s10649-010-9251-8

Pittalis, M., \& Christou, C. (2010). Types of reasoning in 3D geometry thinking and their relation with spatial ability. Educ Stud Math, 191-212. http://dx.doi.org/10.1016/j.ijer.2010.10.001

Pitta-Pantazi, D., \& Christou, C. (2010). Spatial versus object visualisation: The case of mathematical understanding in three-dimensional arrays of cubes and nets. International Journal of Educational Research, 102-114.

Powell, A. B., Francisco, J. M., \& Maher, C. A. (2003). An analytical model for studying the development of learners' mathematical ideas and reasoning using videotape data. Journal of Mathematical Behavior, 22, 405-435. http://dx.doi.org/10.1016/j.jmathb.2003.09.002

Putri, R. I. I. (2011). Pembelajaran Materi Bangun Datar melalui Cerita Menggunakan Pendekatan Matematika Realistik Indonesia (PMRI) di Sekolah Dasar. Jurnal Pendidikan dan Pembelajaran, 18(2). Retrieved from http://journal.um.ac.id/

Revina, S., Zulkardi, Darmawijoyo, \& van Galen, F. (2011). Spatial Visualization Task to Support Students' Spatial Structuring in Learning Volume Measurement. IndoMS. J.M.E, 127-146.

Risma, D. A., Van Eerde, D., Abels, M. J., \& Putri, R. I. I. (2013). Developing Students' Spatial Ability Through the Spatial Visualisation and Spatial Orientation. South East Asia Design/Development Research Conference. Palembang.

Suppiah, K. (2005). Improving and Identifying the Spatial Visualisation Ability of Students'. ITE Teachers' Conference. Singapore: Institute of Technical Education Singapore.

Titus, S. J., \& Horsman, E. (2009). Characterizing and improving spatial visualization skills: special volume on Research on Thinking and Learning in the Geosciences. Journal of Geoscience Education, 57, 242-254. http://dx.doi.org/10.5408/1.3559671

Van Nes, F., \& Van Eerde, D. (2010). Spatial structuring and the development of number sense: A case study of young children working with blocks. The Journal of Mathematical Behavior, 29(3), 145-159. http://dx.doi.org/10.1016/j.jmathb.2010.08.001

\section{Copyrights}

Copyright for this article is retained by the author(s), with first publication rights granted to the journal.

This is an open-access article distributed under the terms and conditions of the Creative Commons Attribution license (http://creativecommons.org/licenses/by/3.0/). 